\title{
Long-term augmentation therapy with Alpha-1 Antitrypsin in an MZ-AAT severe persistent asthma
}

\author{
I. Blanco1, H. Canto1, J. Flóres1, C. Camblor1, V. Cárcaba2, \\ F.J. de Serres 3 , S. Janciauskiene ${ }^{4}$, E.F. Bustillo5
}

ABSTRACT: Long-term augmentation therapy with Alpha1 Antitrypsin in an MZ-AAT severe persistent asthma. I. Blanco, H. Canto, J. Flóres, C. Camblor, V. Cárcaba, F.J. de Serres,S. Janciauskiene, E.F. Bustillo.

A young Caucasian female with severe bronchial asthma and Alpha1-antitrypsin (AAT) deficiency, MZ phenotype, experienced a quick and severe limitation of her physical capacity, which negatively affected her psychological state and social life, though she was under a strong antiasthmatic treatment. Given her declining health status and the significant chronic corticoid administration-related side-effects (including high reduction of muscle mass and bone density), a clinical trial with commercial intravenous AAT was proposed by the patient's doctors, and accepted by the Spanish Ministry of Health, although it this therapy was not approved for MZ phenotypes yet. This new therapy quickly stopped lung function decline rate, dramatically reduced the number of hospital admissions of the patient, suppressed the oral administration of prednisone, reversed the corticosteroid-related health adverse effects, significantly improving her quality of life.

Thus, although AAT replacement therapy is not approved nor indicated for the treatment of bronchial asthma in MZ patients, its favourable effects observed in this isolated case support the hypothesis that bronchial asthma could be due to pathogenic mechanisms related to a protease-antiprotease imbalance, what which could open new perspectives for future research on the field. Monaldi Arch Chest Dis 2008; 69: 4, 178-182.

Keywords: Bronchial asthma, Augmentation therapy with Alpha-1 antitrypsin, SerpinA1, Alpha-1 Antitrypsin phenotypes, Alpha-1 Antitrypsin deficiency augmentation therapy.

1 Unit of Respiratory Diseases, Valle del Nalón Hospital, Langreo, Principado de Asturias, Spain.

2 Department of Internal Medicine, Valle del Nalón Hospital, Riaño-Langreo, Principado de Asturias, Spain.

3 Center for the Evaluation of Risks to Human Reproduction, Environmental Toxicology Program. National Institute of Environmental Health Sciences. Research Triangle Park, NC, U.S.A.

4 Department of Medicine. Malmö University Hospital, Malmö, Sweden.

5 Biostatistics Unit, Central University Hospital of Asturias, Oviedo, Spain.

Correspondence: Ignacio Blanco Blanco, M.D., Department of Internal Medicine, Unit of Respiratory Diseases, Valle del Nalón Hospital, 33920 Polígono de Riaño s/n, Langreo,Principado de Asturias, Spain; e-mail: ignacio.blanco@sespa.princast.es

\section{Introduction}

Alpha-1 Antitrypsin (AAT) deficiency is a genetic disorder, most commonly observed in Caucasian individuals of European origin [1]. The two most prevalent deficiency alleles are PI*S and $\mathrm{PI} * \mathrm{Z}$, both expressing abnormal proteins which fail to fold properly and tend to polymerize in hepatocytes. Thus, $90 \%$ of $\mathrm{Z}$ and $40-50 \%$ of S proteins are retained in the liver. Liver deposits and decreased secretion of AAT into blood can result in serious lung diseases in adults (COPD) and liver diseases in children and adults (from neonatal hepatitis to hepatic cirrhosis and hepatocarcinoma) [2]. Another reported diseases related to AAT deficiency are systemic vasculitis, bronchial asthma, bronchiectasis and necrotizing panniculitis Wegener-type [2]. In clinical practice, $96 \%$ of AAT deficiency patients with adverse health issues have $\mathrm{ZZ}$ phenotype, the remaining $4 \%$ mostly belonging to SZ and other rare deficiency or null phenotypes [1-3].

\section{Case report}

A Caucasian 27-year old cleaning lady started with recurrent dyspnoea, wheezing, cough and chest tightness. A totally reversible and variable spirometric airflow limitation was evidenced, and she was diagnosed with bronchial asthma (fig. 1). In the following years, she was also diagnosed 
with nasal polyps and Aspirin-Sensitive Asthma (ASA). Education for asthma management, avoidance of aspirin, tobacco smoking and second-hand smoke were strongly encouraged and taken into practice. A series of studies to rule out other conditions, mimicking or worsening bronchial asthma, were carried out. These studies included: pulmonary function (spirometry, lung volumes, lung diffusion capacity corrected for alveolar ventilation, and flow-volume curve); chest and paranasal sinus computed axial tomography; nasal endoscopy; blood D-dimer; IgE and anti-Aspergillus IgG serum levels; thyrotropin-releasing factor (TRF), T3 and T4; Anti-Neutrophil Cytoplasm Antibody (ANCA); skin prick and sweet test, to- gether with other routine image and laboratory tests. The results of these studies were normal or negative, except for immune mediated hyperthyroidism. The patient was treated with suppressive thyrostatics medication (carbimazole), and later radioisotope therapy, causing iatrogenic hypothyroidism, easily managed with levothyroxine. Asthma continued, however, to be poorly controlled, with frequent night symptoms, daily attacks of dyspnoea and limitation of physical exertion. Pulmonary function significantly worsened, and the patient needed to visit the emergency services frequently for her asthma attacks, even experiencing several asthma-related hospital admissions (fig. 1). She was prescribed long-term daily prednisone

\begin{tabular}{|c|c|c|c|c|c|}
\hline $\begin{array}{l}\text { Year } \\
\text { (age - } \\
\text { years) }\end{array}$ & Diagnosis & Comorbidities and events & Treatment & $\begin{array}{l}\text { Emergency } \\
\text { Service } \\
\text { attention for } \\
\text { asthma attack }\end{array}$ & $\begin{array}{l}\text { Hospital } \\
\text { admissions for } \\
\text { asthma attack }\end{array}$ \\
\hline $\begin{array}{l}1989 \\
(27)\end{array}$ & $\begin{array}{l}\text { Moderate } \\
\text { persistent } \\
\text { asthma }\end{array}$ & $\begin{array}{l}\text { Reversible and variable spirometric } \\
\text { airflow limitation (FEV1: } 61 \text { to } 91 \% \text { ) }\end{array}$ & $\begin{array}{l}\text { LAI B2 \& SAI B2 + Inh cort } \\
\text { (medium doses) }\end{array}$ & & \\
\hline $\begin{array}{c}1993 \\
(31)\end{array}$ & $\begin{array}{l}\text { Nasal } \\
\text { polyps and } \\
\text { Aspirin- } \\
\text { sensitive } \\
\text { asthma } \\
\text { (ASA) }\end{array}$ & $\begin{array}{l}\text { Accelerated FEV1 decline } \\
\text { \& fixed obstruction }\end{array}$ & $\begin{array}{c}\text { LAI B2 \& SAI B2 + Inh cort (high } \\
\text { doses) + Oral Theophyline + } \\
\text { Montelukast }\end{array}$ & 1 & \\
\hline $\begin{array}{l}1999 \\
(37)\end{array}$ & & $\begin{array}{l}\text { Hyperthyroidism } \\
\text { (radioisotope therapy) } \\
\text { Resection of nasal polyps }\end{array}$ & Id. + daily oral Prednisone & 3 & 1 \\
\hline $\begin{array}{l}2000 \\
(38)\end{array}$ & & latrogenic hypothyroidism & Id. + L-thyroxine & 5 & 2 \\
\hline $\begin{array}{l}2001 \\
(39)\end{array}$ & & $\begin{array}{c}\text { Steroid-induced Cushing's syndrome, } \\
\text { myopathy and osteoporosis } \\
\text { development }\end{array}$ & & 6 & \\
\hline $\begin{array}{l}2002 \\
(40)\end{array}$ & $\begin{array}{l}\text { MZ-AAT } \\
\text { deficiency }\end{array}$ & & & 8 & 2 \\
\hline $\begin{array}{c}2003 \\
(41)\end{array}$ & & $\begin{array}{l}\text { Control Chest computed axial } \\
\text { tomography, normal limits } \\
\text { (not emphysema) }\end{array}$ & $\begin{array}{l}\text { Id. + AAT aumentation therapy } \\
\text { infusions }\end{array}$ & 8 & 2 \\
\hline $\begin{array}{c}2004 \\
(42)\end{array}$ & & $\begin{array}{l}\text { Daily oral Prednisone removed. Steroid- } \\
\text { induced osteoporosis and Cushing's } \\
\text { syndrome improvement. }\end{array}$ & $\begin{array}{l}\text { LAI B2 \& SAI B2 + Inh cort (high } \\
\text { doses) + Montelukast + } \\
\text { L-thyroxine + AAT augmentation } \\
\text { therapy infusions }\end{array}$ & 3 & \\
\hline $\begin{array}{l}2005 \\
(43)\end{array}$ & & $\begin{array}{l}\text { Progressive improvement of } \\
\text { Quality of Llife } \\
\text { Lung function decline stopped }\end{array}$ & & 2 & \\
\hline $\begin{array}{l}2006 \\
(44)\end{array}$ & & $\begin{array}{l}\text { Decreased Emergency attentions and } \\
\text { Hospital admissions }\end{array}$ & & 1 & \\
\hline $\begin{array}{l}2007 \\
(45)\end{array}$ & & & & 2 & $\begin{array}{c}1 \\
\text { (pneumonia) }\end{array}$ \\
\hline
\end{tabular}

Fig. 1. - Arrows show several positive effects of long-term AAT augmentation therapy throughout the clinical history of the patient. Abbreviations: AAT: Alpha1-antitrypsin. PI: Proteinase Inhibitor. COPD: Chronic Obstructive Pulmonary Disease. ASA: Aspirin-Sensitive Asthma. AQL: Asthma Quality of Life questionnaire. LAI B2: Long-Acting Inhaled B2-agonist. SAI B2: Short-Acting Inhaled B2-agonists. Inh cort: Inhaled Corticosteroid. Id.: Latin, short for "idem", "the same". FEV 1 : Forced Expiratory Volume in 1 second. 
tablets (15-30 mg a day). However, asthma continued to be out of control and bronchial obstruction became permanent; and even some side-effects of glucocorticoid drugs appeared in the following months, including central obesity and high reduction of muscle mass and bone density. All these facts made the patient experience a severe limitation of her physical capacity, which negatively affected her mental state and social activities and, thus, her personal life. Her brother and mother also suffered from bronchial asthma, which raised suspicions about the family story and led to the performance of an AAT deficiency study. Isoelectric-focusing and nephelometry showed that the patient had an MZ deficiency phenotype with intermediate low serum AAT concentrations. A second phenotyping confirmed the previous diagnosis, and a genotyping made through PCR, sequencing exons II-V of the AAT gene, diagnosed a genotype $M_{3} Z$. A new chest computed axial tomography to rule out pulmonary emphysema and/or other intercurrent complications was within the normal limits. These findings, together with the unfavourable evolution of the patient, led doctors to consider a therapeutic trial with AAT augmentation therapy to check its effectiveness, although it was not indicated for MZ heterozygotes. Once the Spanish Drug Agency (Agencia Española del Medicamento) of the Ministry of Health gave its approval, a trial with commercial AAT was made, with a 60 $\mathrm{mg} / \mathrm{Kg} /$ week dose for the first two weeks and 120 $\mathrm{mg} / \mathrm{biweekly}$ dose for 7 months. As the results of this trial were significantly favourable, with very good tolerance and without any drug-related adverse effect, the Spanish authorities agreed with the treatment to be continued. In the latest four years, the uninterrupted administration of AAT infusions stopped lung function decline rate. Thus, her FEV ${ }_{1}$ (expressed by mean and standard deviation) from 1991 to 1994 (period 1) was 69\% (17); in 1995-2003 (period 2) 43\% (5.14)], and from 2004 (once the AAT augmentation therapy began) to 2007 (period 3), her $\mathrm{FEV}_{1}$ rose up to $52 \%$ (3.75). Statistical significance was found between period 1 and period $2(\mathrm{p}=0.000)$, period 1 and period $3(\mathrm{p}=0.000)$, and between period 2 and period $3(\mathrm{p}=0.001)$. As expected, the augmentation therapy increased the AAT serum levels of the patient (measured by nephelometry and expressed in $\mathrm{mg} / \mathrm{dL}$ ) from basal values of 0.78 (0.04) to $1.08(0.10)$ pre-infusions, and 2.61 (0.34) post-infusions. In addition, AAT augmentation therapy significantly reduced the number of emergency consultations and hospital admissions (i.e., 22 emergency consultations in 2001-2003 vs. 8 in 2004-2007; and 4 hospital admissions in 2002-2003 vs 1 in the 2004-2007). Interestingly, AAT augmentation therapy reduced the need for prednisone shortly after the beginning of the augmentation therapy, facilitating the elimination of chronic corticoid administration-related side-effects and progressively reducing the very high score of Asthma Quality of Life (AQL) in 2003 from 10 to 3 points in 2007 (fig. 2).

\section{Discussion}

The only approved indication for AAT-augmentation therapy with purified AAT, prepared from donors' serum, is severe AAT deficiency-related pulmonary emphysema (phenotypes ZZ, Null-null, and Z-null) [1]. Although the lack of large randomized controlled trials has precluded, to date, the definitive demonstration of the clinical efficacy of intravenous infusions of AAT augmentation therapy, substantial evidence supporting its use in individuals with moderate airways obstruction has been accumulated and, despite its high cost, it remains the only US FDA-approved treatment option for patients with severe AAT-deficiency [4]. On the other hand, AAT-augmentation therapy is considered to be safe and effective in patients with AAT deficiency and, necrotizing panniculitis [1]. In addition, a ZZ case with persisting multi-organ vasculitis has been reported to dramatically respond to the administration of purified AAT [1]. Lastly, a recent observation indicated that augmentation therapy was effective for the control of long-term fibromyalgia symptoms in a pair of female sisters with ZZ phenotype [5].

Although $\mathrm{MZ}$ phenotype-related risk remains uncertain, in a large group of subjects with AAT deficiency registered in the Alpha-1 Foundation Research Registry, 44.6\% ( $=338)$ reported to be diagnosed of asthma, and asthma was three times more prevalent in the $\mathrm{MZ}$ group than in the $\mathrm{ZZ}$ group [6]. A recent meta-analysis about the risk of Chronic Obstructive Pulmonary Disease (COPD) in $\mathrm{MZ}$ heterozygous individuals concluded that case-control studies showed increased odds of $\mathrm{COPD}$ in $\mathrm{MZ}$ individuals, although this finding was not confirmed in any cross sectional study. All these results were consistent with a small increase in the risk of COPD for all MZ individuals or with a larger risk in a subset of individuals, although future studies on smoking which include other COPD related phenotypes are required to conclusively determine the risk of COPD in MZ heterozygotes [7].

An imbalance between elastase and AAT in asthmatic subjects has been described, and airway inflammation has been associated with high levels of active elastase detected in induced sputum, obtained from asthmatic patients compared to controls [8]. In addition to its proteolytic properties, neutrophil elastase is a potent secretagogue and pro-inflammatory serine proteinase. Moreover, both neutrophils and eosinophils are abundant in chronic inflammatory responses to asthma, and recent evidence suggests that both neutrophilic and eosinophilic inflammation persists in the airways of patients with severe asthma and that neutrophil proteases (such as: elastase, cathepsin $\mathrm{G}$ and proteinase 3) activate peripheral blood eosinophils to produce superoxide and proinflammatory cytokines, which can further aggravate airway inflammation [9]. On the other hand, it is well known that, apart from its contractile properties, the Airway Smooth Muscle (ASM) is critically involved in the pathogenesis of asthma by producing inflammatory mediators. A 
Forced Expiratory Volume in 1 second $\left(F E V_{1}\right)$ in \% of predicted

A

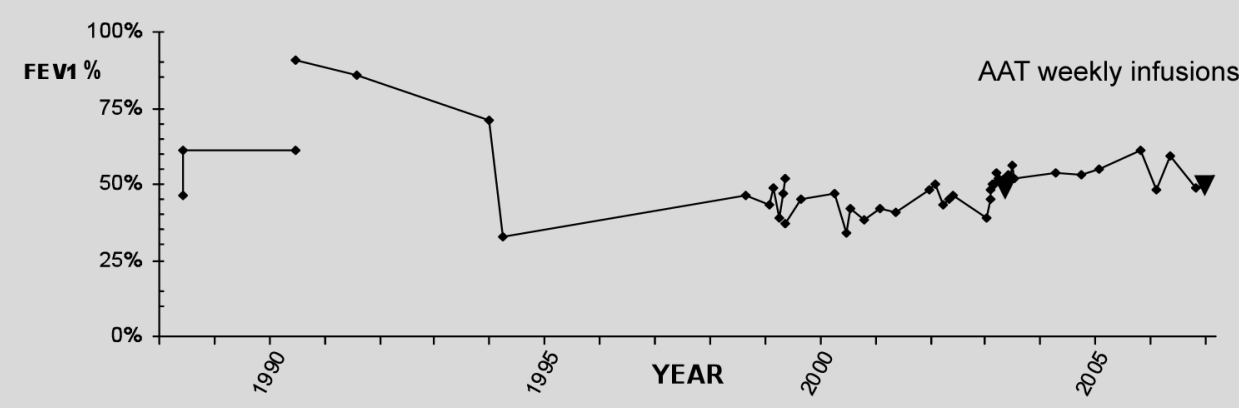

AAT serum concentration pre \& post AAT weekly infusions

B

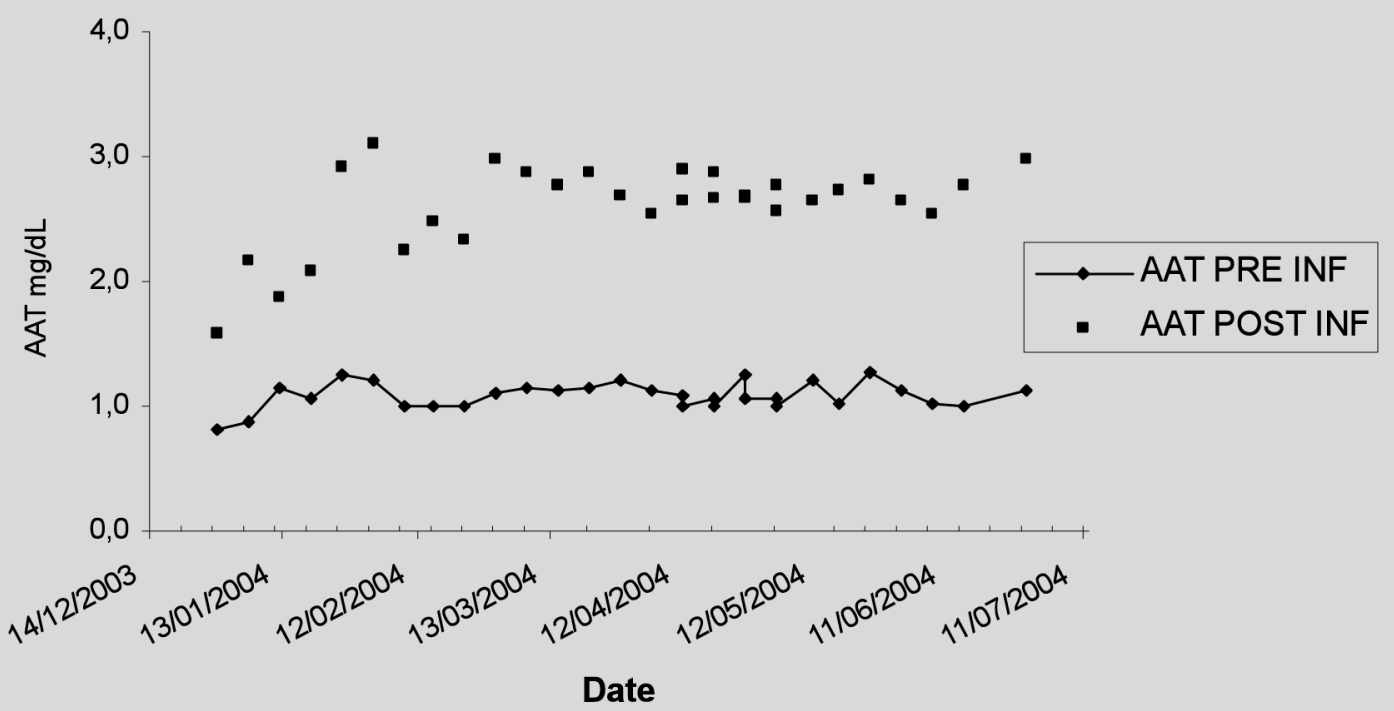

C

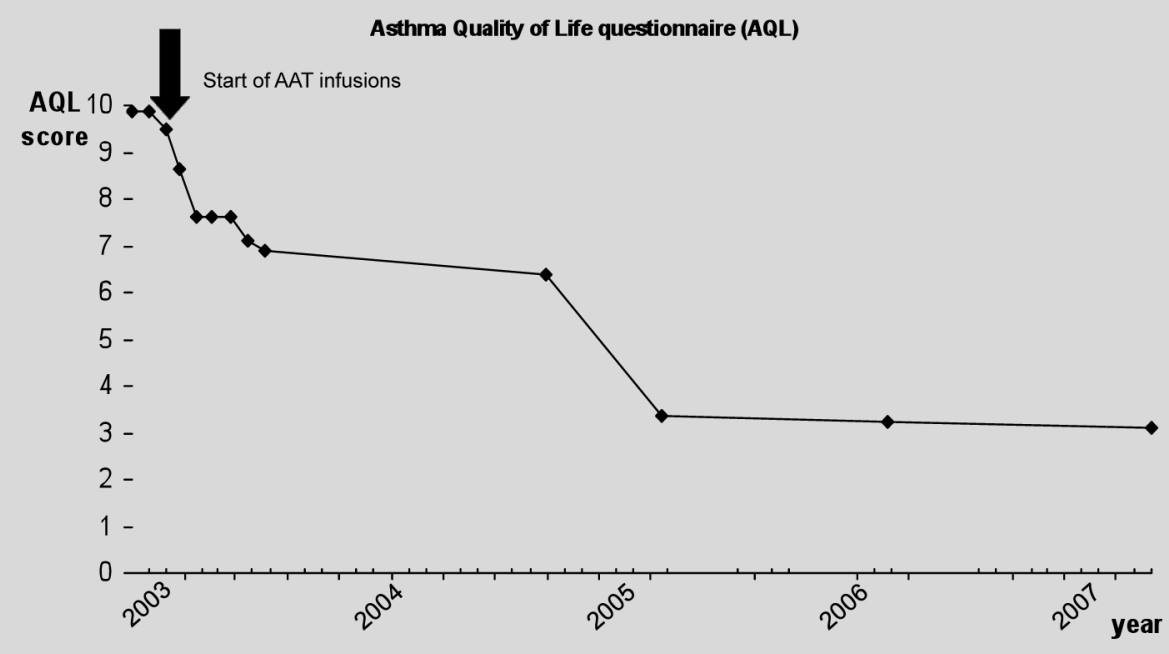

Fig. 2. - A. $\mathrm{FEV}_{1}$ values (expressed by mean and standard deviation) in 3 chronological periods. Period 1, years 1991-1994: [69\% (17)]; Period 2, 1995-2003: [43\% (5.14)]; Period 3, 2004-2007: [52\% (3.75)]. Statistical significance found among Period 1 vs Period 2 ( $p=0.000)$, Period 1 vs Period 3 ( $\mathrm{p}=0.000$ ); and Period 2 vs. Period 3 ( $\mathrm{p}=0.001$ ). B. AAT serum concentrations measured by nephelometry (reference values: $120-200$ $\mathrm{mg} / \mathrm{dL}$ ): basal $0.78(0.04)$, pre-infusions: $1.08(0.10)$, post-infusions: $2.61(0.34)$. C. AQL. Scores slowly decreased from 10 points in the 2 months previous to the infusions, to 6.37 at the end of the trial, and to 3.12 in December of 2007. 
study aimed at investigating the mitogenic effect of elastase on ASM cells showed that human neutrophil elastase is mitogenic for ASM cells through Extracellular signal-Regulated Kinase (ERK) signalling pathway [10]. In this sense, it has been also demonstrated that neutrophil elastase enhances TGF-beta1 (a protein which plays an important role in controlling the immune system) release by upregulating TGF-beta1 gene [11].

Previous studies reported that the development of Airway Hyper-Responsiveness (AHR) after antigen challenge in an allergic sheep was associated with increased Tissue Kallikrein activity (TK) and decreased AAT activity in Bronchoalveolar fluid (BAL) and that the administration of AAT might reduce TK activity and block $\mathrm{AHR}$, raising the possibility that in vivo AAT could regulate TK activity and allergen-induced AHR [12]. Other study showed that the allergic stimulation of airways provokes the release of elastase, TK, and Reactive Oxygen Species (ROS), which could reduce AAT activity and contribute to AHR [13]. However, the treatment with $10 \mathrm{mg}$ of recombinant AAT blocked the bronchoconstriction caused by elastase, high-molecular-weight kininogen, and ROS, and the AHR induced by ROS and antigen. One milligram of AAT was ineffective. According to the author's comments these in vivo data suggested that AAT can be important in the regulation of airway responsiveness [13].

In conclusion, the favourable effects of the AAT augmentation therapy observed in the present case, although they do not show a casual relation between $\mathrm{MZ}$ phenotypes, bronchial asthma and AAT augmentation therapy, they support the hypothesis of a possible protease-antiprotease imbalance in the pathogenesis of asthma and could open new perspectives for future studies on asthma mechanisms.

The potential therapeutic use of inhibitors of neutrophil elastase in the inflammatory diseases of the airway is currently controversial. In addition to the natural inhibitors of elastase, such as AAT and the secretory leukoprotease inhibitor, recombinant versions of naturally occurring inhibitors and synthetic small molecule inhibitors are potential therapies for inflammatory respiratory diseases. For recombinant proteins, aerosol administration could be the preferred method of delivery, although the inhaled mode of delivery can complicate the determination of dose responsiveness and, thus, the evaluation of the safety and the efficacy of these agents. In addition to the aerosolization issue, there remain other significant barriers to the successful deployment of these agents in clinical trials. These include the need for high standards for the purification of recombinant proteins, the lack of understanding of the interaction with airway secretions, the controversy over the role of neutrophil elastase in the pathogenesis of non-hereditary COPD and asthma, and the remaining evidence for the safety and the efficacy of new classes of systemically delivered small molecules [14].
Acknowledgements: The authors acknowledge the expert editorial assistance of Ms. Jimena Blanco Fueyo (MA Universite de Geneve, Switzerland).

Conflict of Interest Statement: None of the authors has a financial relationship with any commercial entity with an interest in the subject of the present manuscript.

\section{References}

1. de Serres FJ, Blanco I, Fernández-Bustillo E.PI S and PI Z alpha-1 antitrypsin deficiency worldwide. A review of existing genetic epidemiological data. Monaldi Arch Chest Dis 2007; 67: 184-208.

2. American Thoracic Society; European Respiratory Society. American Thoracic Society/European Respiratory Society statement: standards for the diagnosis and management of individuals with alpha-1 antitrypsin deficiency. Am J Respir Crit Care Med 2003; 168: 818900.

3. Janciauskiene SM, Stevens T, Blanco I. New insights into the biology of $\alpha 1$-antitrypsin and its role in chronic obstructive pulmonary disease. Curr Respir Med Rev 2007; 3: 147-158.

4. Blanco I., Canto H., de Serres F.J., Bustillo E.F., Rodríguez M.C. Alpha-1-antitrypsin replacement therapy efficiently controls fibromyalgia symptoms in two PI ZZ alpha-1-antitrypsin deficiency patients. J Rheumatol 2004; 31: 2082-2085.

5. Heresi GA, Stoller JK. Augmentation therapy in alpha1 antitrypsin deficiency. Expert Opin Biol Ther 2008; 8: 515-526.

6. Eden E, Strange C, Holladay B, Xie L. Asthma and allergy in alpha-1 antitrypsin deficiency. Respir Med 2006; 100: 1384-1391.

7. Hersh CP, Dahl M, Ly NP, Berkey CS, Nordestgaard $\mathrm{BG}$, Silverman EK. Chronic obstructive pulmonary disease in alpha1-antitrypsin PI MZ heterozygotes: a metaanalysis. Thorax 2004; 59: 843-849.

8. Vignola AM, Bonanno A, Mirabella A, et al. Increased levels of elastase and alpha1-antitrypsin in sputum of asthmatic patients. Am J Respir Crit Care Med 1998; 157: 505-11.

9. Hiraguchi Y, Nagao M, Hosoki K, Tokuda R, Fujisawa T. Neutrophil Proteases Activate Eosinophil Function in vitro. Int Arch Allergy Immunol 2008; 146 Suppl 1: $16-21$.

10. Huang $\mathrm{CD}$, Chen $\mathrm{HH}$, Wang $\mathrm{CH}$, et al. Human neutrophil-derived elastase induces airway smooth muscle cell proliferation. Life Sci 2004; 74: 2479-2492.

11. Lee KY, Ho SC, Lin HC, et al. Neutrophil-derived elastase induces TGF-betal secretion in human airway smooth muscle via NF-kappaB pathway. Am J Respir Cell Mol Biol 2006; 35: 407-414

12. Forteza R, Botvinnikova Y, Ahmed A, et al. The interaction of alpha 1-proteinase inhibitor and tissue kallikrein in controlling allergic ovine airway hyperresponsiveness. Am J Respir Crit Care Med 1996; 154: 36-42.

13. Scuri M, Botvinnikova Y, Lauredo IT, Abraham WM. Recombinant alpha 1-proteinase inhibitor blocks antigen- and mediator-induced airway responses in sheep. $J$ Appl Physiol 2002; 93: 1900-1906.

14. Chughtai B, O'Riordan TG. Potential role of inhibitors of neutrophil elastase in treating diseases of the airway. J Aerosol Med 2004; 17: 289-298. 